\title{
Stent and leaflet stresses in a 26-mm first-generation balloon-expandable transcatheter aortic valve
}

\author{
Yue Xuan, $\mathrm{PhD},{ }^{\mathrm{a}}$ Kapil Krishnan, $\mathrm{PhD},{ }^{\mathrm{a}}$ Jian Ye, MD, ${ }^{\mathrm{b}}$ Danny Dvir, MD, ${ }^{\mathrm{c}}$ Julius M. Guccione, $\mathrm{PhD},{ }^{\mathrm{a}}$ \\ Liang Ge, $\mathrm{PhD},{ }^{\mathrm{a}}$ and Elaine E. Tseng, $\mathrm{MD}^{\mathrm{a}}$
}

\begin{abstract}
Objective: Transcatheter aortic valve replacement is established therapy for highrisk and inoperable patients with severe aortic stenosis, but questions remain regarding long-term durability. Valve design influences durability. Increased leaflet stresses in surgical bioprostheses have been correlated with degeneration; however, transcatheter valve leaflet stresses are unknown. From 2007 to 2014, a majority of US patients received first-generation balloon-expandable transcatheter valves. Our goal was to determine stent and leaflet stresses in this valve design using finite element analyses.
\end{abstract}

Methods: A 26-mm Sapien Transcatheter Heart Valve (Edwards Lifesciences, Inc, Irvine, Calif) underwent high-resolution microcomputed tomography scanning to develop precise 3-dimensional geometry of the leaflets, the stent, and the polyethylene terephthalate elements. The stent was modeled using 3dimensional elements and the leaflets were modeled using shell elements. Stent material properties were based on stainless steel, whereas those for leaflets were obtained from surgical bioprostheses. Noncylindrical Sapien valve geometry was also simulated. Pressure loading to $80 \mathrm{~mm} \mathrm{Hg}$ and $120 \mathrm{~mm} \mathrm{Hg}$ was performed using ABAQUS finite element software (Dassault Systèmes, Waltham, Mass).

Results: At $80 \mathrm{~mm} \mathrm{Hg}$, maximum principal stresses on Sapien leaflets were 1.31 megaspascals (MPa). Peak leaflet stress was observed at commissural tips where leaflets connected to the stent. Maximum principal stresses for the stent were 188.91 MPa and located at stent tips where leaflet commissures were attached. Noncylindrical geometry increased peak principal leaflet stresses by $16 \%$.

Conclusions: Using exact geometry from high-resolution scans, the 26-mm Sapien Transcatheter Heart Valve showed that peak stresses for both stent and leaflets were present at commissural tips where leaflets were attached. These regions would be prone to leaflet degeneration. Understanding stresses in first-generation transcatheter valves allows comparison to future designs for relative durability. (J Thorac Cardiovasc Surg 2017;153:1065-73)

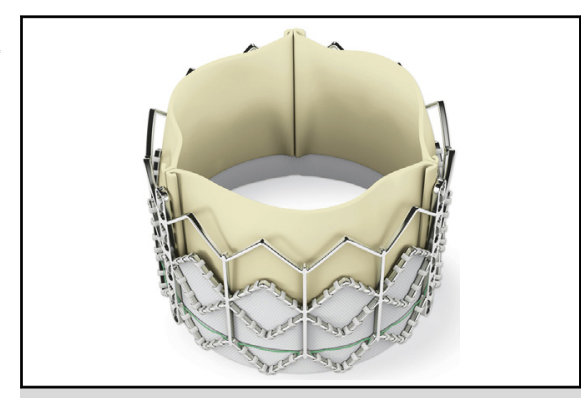

The 26-mm Sapien Transcatheter Heart Valve (Edwards Lifesciences, Irvine, Calif).

\section{Central Message}

First-generation Sapien valves (Edwards Lifesciences, Irvine, Calif) have peak stresses at commissures that may initiate eventual bioprosthetic calcification and degeneration.

\section{Perspective}

With transcatheter valves moving to use for intermediate-risk patients, questions arise regarding long-term durability. Stress analyses are important for evaluating durability relative to surgical bioprotheses or newer devices. We demonstrate that peak leaflet stresses in firstgeneration Sapien valves (Edwards Lifesciences, Irvine, Calif) occur at leaflet commissures at stent attachment sites, suggesting regions prone to degeneration.

See Editorial Commentary page 1074.

\footnotetext{
From the ${ }^{\text {a Department }}$ of Surgery, University of California San Francisco and San Francisco VA Medical Centers, San Francisco, Calif; ${ }^{b}$ Division of Cardiovascular Surgery, St Paul's Hospital and Vancouver General Hospital, Vancouver, British Columbia, Canada; and ${ }^{\mathrm{c} D i v i s i o n}$ of Cardiology, University of Washington, Seattle, Wash.

Supported by the University of California Office of the President, University of California Proof of Concept grant No. 246590.

Presented at Transcatheter Cardiovascular Therapeutics 2014, Washington, DC, September 14, 2014.

Received for publication May 28, 2016; revisions received Nov 25, 2016; accepted for publication Dec 5, 2016; available ahead of print Jan 17, 2017.

Address for reprints: Elaine E. Tseng, MD, Division of Cardiothoracic Surgery, University of California San Francisco and San Francisco VA Medical Center, 4150 Clement St, 112D, San Francisco, CA 94121 (E-mail: Elaine.Tseng@ucsf.edu). $0022-5223 / \$ 36.00$

Copyright (c) 2017 by The American Association for Thoracic Surgery http://dx.doi.org/10.1016/j.jtcvs.2016.12.016
}

Transcatheter aortic valve replacement (TAVR) was first performed in a human of prohibitive surgical risk in 2002 using a balloon-expandable stainless steel stent with equine pericardial leaflets; specifically, the Cribier-Edwards (Edwards Lifesciences, Inc, Irvine, Calif) transcatheter aortic valve (TAV). ${ }^{1}$ Subsequently, equine leaflets were replaced

Scanning this QR code will take you to a video for the article. 


$\begin{array}{ll}\text { Abbreviations and Acronyms } \\ \text { 3D } & =3 \text { dimensional } \\ \mathrm{FEA} & =\text { finite element analysis } \\ \mathrm{FE} & =\text { finite element } \\ \mathrm{kPa} & =\text { kilopascal } \\ \mathrm{MPa} & =\text { megapascal } \\ \mathrm{Micro}-\mathrm{CT} & =\text { microcomputed tomography } \\ \text { PARTNER } & =\text { Placement of Aortic Transcatheter } \\ & \text { Valves trial } \\ \mathrm{TAV} & =\text { transcatheter aortic valve } \\ \text { TAVR } & =\text { transcatheter aortic valve replacement }\end{array}$

with bovine pericardium and the first-generation Edwards Sapien valve (Edwards Lifesciences, Inc) was created. This first-generation TAV was used in the pivotal Placement of Aortic Transcatheter Valves (PARTNER) randomized trials in the United States comparing TAVR to medical therapy in inoperable patients and comparing TAVR to surgical aortic valve replacement in high-risk patients beginning in April 2007., ${ }^{2,3}$ TAVR was superior to medical therapy ${ }^{4,5}$ for severe aortic stenosis in inoperable patients and equivalent to surgery in high-risk patients. ${ }^{6}$ The secondgeneration TAV, Edwards Sapien XT (Edwards Lifesciences, Inc), modified the design to reduce stent profile using cobalt-chromium, and changed its leaflet design from an open to a semiclosed position. Sapien XT was approved for commercial use in June 2014; thus, presently in the United States, thousands of patients have had the original Sapien TAV implanted.

Because TAVR demonstrated equipoise with surgery in intermediate-risk patients ${ }^{7}$ and will proceed to lower-risk surgical patients, a major concern is TAV long-term durability. Durability in surgical bioprostheses has been extensively studied. $^{8-10}$ Pathologically, bioprosthetic degeneration involves leaflet cusp calcification and stiffening, and leaflet tearing. Areas of increased stresses correlate with regions of calcific degeneration or leaflet tearing. ${ }^{11,12}$ Understanding TAV leaflet stresses is the first step toward understanding TAV durability and the regions prone to degeneration. Presently, TAV leaflet stresses are unknown and cannot be directly measured, but can be determined through finite element analyses (FEAs). FEA is an essential method to obtain valuable data about complicated real-world systems that would otherwise be impossible to directly measure. FEA when applied to medical device designs can be used to calculate stresses and investigate potential failure modes and locations. Finite element (FE) models require accurate 3-dimensional (3D) geometry in the zero-stress state, material properties, and physiologic loading conditions. Our goal was to determine stent and leaflet stresses in the firstgeneration 26-mm Edwards Sapien TAV (Edwards Lifesciences, Inc), which was implanted during the PARTNER trial and received initial TAVR commercialization in the United States. In addition, noncylindrical TAV shape after implantation in the calcified aortic root has been observed, which can cause moderate postoperative paravalvular regurgitation. ${ }^{13} \mathrm{~A}$ distorted implanted TAV may experience higher stress levels. ${ }^{14}$

\section{MATERIALS AND METHODS}

We obtained a commercial 26-mm Edwards Sapien valve (external diameter, $26 \mathrm{~mm}$ and height, $16.1 \mathrm{~mm}$ ) that consisted of 3 components: stainless steel stent, polyethylene terephthalate covering, and bovine pericardial leaflets. Physical measurements were taken and the suture connections between different components were studied to enable accurate modeling of the valve. The process to determine TAV stress distribution included micro-computed tomography (micro-CT) scanning of the 26$\mathrm{mm}$ Sapien valve at $0 \mathrm{~mm} \mathrm{Hg}$; development of TAV mesh using 3D geometry of the leaflets, stent, and polyethylene terephthalate; application of material properties of the stent and leaflets followed by systemic pressure loading; and FEA using a finite element (FE) solver.

\section{Sapien TAV Mesh Generation}

A fully expanded Sapien valve $(26 \mathrm{~mm})$ was imaged under $0 \mathrm{~mm} \mathrm{Hg}$ pressure with a desktop cone-beam micro-CT scanner (microCT-40; Scanco Medical AG, Baseldorf, Switzerland) in different orientations and intensities to distinguish stent and leaflet geometries. Scan settings used were: $45 \mathrm{kVp}$ for x-ray energy, $200 \mu \mathrm{A}$ for x-ray current, $0.5 \mathrm{~mm}$ aluminum filter, $50 \mathrm{~mm}$ field of view, $50 \mu \mathrm{m}$ voxel size, and $200 \mathrm{~ms}$ integration time. Highresolution Digital Imaging and Communications in Medicine radiologic images (voxel size, $50 \times 50 \times 50 \mu \mathrm{m}$ ) were imported into MeVisLab, an open source surface reconstruction software (http://www.mevislab.de/). Digital Imaging and Communications in Medicine files were scanned individually to separate TAV stent versus leaflets materials to obtain the most accurate representation of their respective geometries. Stent and leaflet surfaces were combined using suture lines as a reference point for leaflet orientation. The reconstructed surface was then imported into GeoMagic Design, (3DSystems, Rock Hill, SC), a computer-aided design software, to refine and create the $3 \mathrm{D}$ geometric volume with accurate size and thickness at zero stress. The refined geometries of leaflets, stent, and polyethylene terephthalate were then imported into HyperMesh (Altair Engineering, Troy, Mich) to generate TAV mesh with 46,443 total elements.

\section{Constitutive Model and Material Properties}

TAV stent and leaflets were assigned material properties. Sapien valves use leaflets made of specially treated bovine pericardium to resist calcification and that proprietary process was the same as for corresponding surgical Carpentier-Edwards Magna pericardial valves (Edwards Lifesciences, Inc). Biaxial stretch testing of these surgical valves was performed to determine material properties of TAV leaflets to avoid destroying the leaflets of the 26-mm Sapien. Methods of biaxial stretching have been previously described. ${ }^{13}$ TAV leaflets were assumed to be anisotropic, nonlinear, hyperelastic, and orthotropic materials. The material's response to stress was described mathematically by a set of constitutive equations derived from strain energy function $W$. Using Fung-type hyperelastic material, $W$ was described as

$$
\begin{gathered}
W=\frac{c}{2}\left[e^{Q}-1\right]+\frac{1}{D}\left(\frac{J^{2}-1}{2}-\ln J\right) \\
Q=c_{i} E_{j k} E_{l m}
\end{gathered}
$$

where $c, c_{i}$, and $D$ are material parameters; $E_{j k}$ and $E_{l m}$ are quadratic form of Green-Lagrangian strain; and $J$ is the determinant of deformation tensor. 
TABLE 1. Material constants for leaflets and stent

\begin{tabular}{cccccc}
\hline \multicolumn{7}{c}{ Leaflet } \\
\hline$c_{1}$ & $c_{\boldsymbol{2}}$ & $\boldsymbol{c}_{3}$ & $\boldsymbol{c}_{\boldsymbol{4}}$ & $\boldsymbol{c}_{\boldsymbol{5}}$ & $\boldsymbol{c}_{\boldsymbol{6}}$ \\
\hline 62.28 & 26.97 & 132.12 & 0.01 & 0.01 & 0.01 \\
$\boldsymbol{c}_{\boldsymbol{7}}$ & $\boldsymbol{c}_{\boldsymbol{8}}$ & $\boldsymbol{c}_{\boldsymbol{9}}$ & $\boldsymbol{c}$ & $\boldsymbol{D}$ & \\
\hline 31.14 & 0.01 & 0.01 & 5.01 & 0.000001 & \\
\hline
\end{tabular}

\begin{tabular}{ccccc}
\hline $\begin{array}{c}\text { Soung's } \\
\text { modulus, GPa }\end{array}$ & $\begin{array}{c}\text { Poisson's } \\
\text { ratio }\end{array}$ & $\begin{array}{c}\text { Yield } \\
\text { stress, MPa }\end{array}$ & $\begin{array}{c}\text { Ultimate } \\
\text { stress, MPa }\end{array}$ & $\begin{array}{c}\text { Strain } \\
\text { at break }\end{array}$ \\
\hline 200 & 0.3 & 330 & 676 & 0.5 \\
\hline
\end{tabular}

GPa, Gigapascal; $M P a$, megapascal.

Material parameters in the above equations are obtained from biaxial tensile tests previously conducted in our laboratory (listed in Table 1). Stainless steel material properties were used for the stent and it was modeled using an elastic-plastic material with Young's modulus, Poisson's ratio, yield stress, and hardening parameters as material constants (Table 1).

\section{FE Simulation}

FE simulations were performed using the commercial FE solver, ABAQUS (Dassault Systèms, Waltham, Mass). Stent geometry was modeled using 3D brick elements, whereas leaflet geometry was modeled using nonlinear shell elements. Mesh sizes chosen for the stent and leaflets were 0.5 and $0.25 \mathrm{~mm}$, respectively. Contact definitions between the leaflets and between leaflet and stent were investigated to choose one most accurately representing the overall behavior. Leaflet nodes were connected to the stent using a TIE contact (coefficient of friction value, 0.1). TAV leaflet geometries were sutured to the polyethylene terephthalate mesh at the bottom (Figure 1) and tied to stent geometry at the top. The TAV leaflet mesh was subdivided into 3 distinct regions (Figure 1,A) to study stress distribution due to pressure loading on the sutured edges, upper free edge region, and lower belly region.

To simulate elliptical shape of TAV after deployment based on clinical post-TAVR patient computed tomography data on Sapien valves, ${ }^{15}$ additional displacement was applied to specified portions of the stent. The outline of the stent and sutured leaflets were deployed to noncylindrical shape with nonuniform radial distances. After deployment, simulations were performed to determine TAV stresses based on arterial pressure on a manufactured TAV without crimping and balloon expansion. Nondistorted and distorted TAV stent and leaflets were exposed to systemic
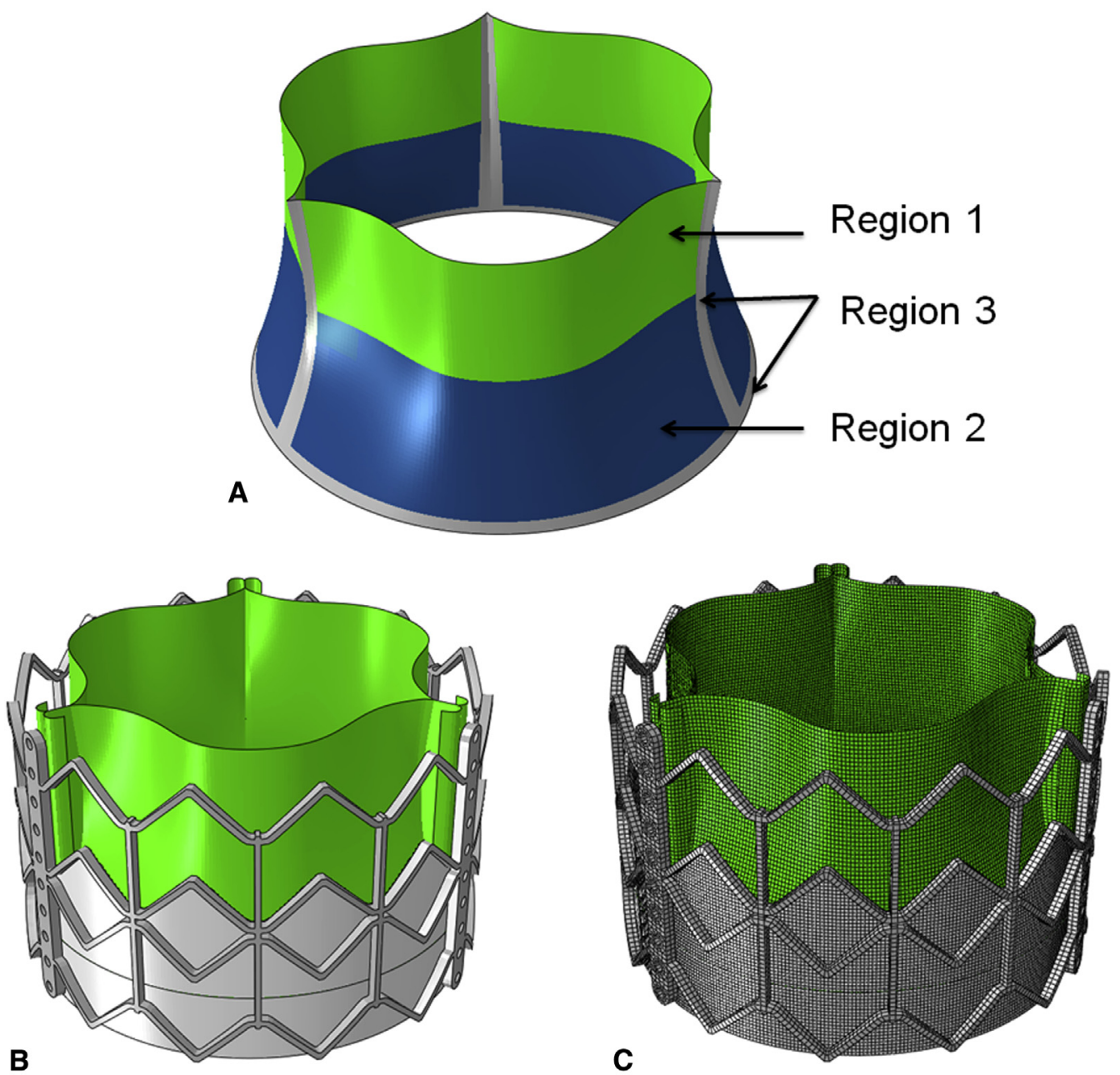

FIGURE 1. A, Regions of interest studied for stress distribution in leaflets. Region $1=$ upper leaflet free edges, region $2=$ lower leaflet belly, and region 3 = sutured leaflet edges. B, Geometry of 26-mm Sapien Transcatheter Aortic Valve (Edwards Lifesciences, Irvine, Calif). C, Transcatheter aortic valve finite element mesh. 
pressure of $80 \mathrm{~mm} \mathrm{Hg}$ and $120 \mathrm{~mm} \mathrm{Hg}$ using quasistatic pressure loading. Boundary conditions were applied to the TAV stent to prevent any rigid body motion. The longitudinal displacement of the 9 proximal nodes of the stent were constrained to represent TAV deployment into diseased native valves.

\section{RESULTS}

The 26-mm Sapien valve geometry, including TAV leaflets, the stent, and the polyethylene terephthalate elements, were precisely reconstructed and aligned. Leaflets were attached to polyethylene terephthalate and the stent along suture lines. Data presented here were from a single optimized simulation after mesh refinement studies, adjusting the material parameters and boundary conditions. The geometry of the 26-mm Sapien valve and corresponding FE mesh are shown in Figure 1. Loading and boundary conditions were applied to stent and leaflet assembly. Maximum and minimum principal stresses for entire leaflet assembly and each subregion, are shown for $80 \mathrm{~mm} \mathrm{Hg}$ and $120 \mathrm{~mm} \mathrm{Hg}$ (using quasistatic loading condition) in Figure 2. High stress concentration locations were determined. Maximum principal stresses across entire leaflet, including sutured regions, at 80 and $120 \mathrm{~mm} \mathrm{Hg}$, were 2.54 and 3.06 megapascal
(MPa), respectively (Figure 3, $I$ and $K$ ). Minimum principal stresses across the entire leaflet, including sutured regions, at 80 and $120 \mathrm{~mm} \mathrm{Hg}$, were -0.78 and $-1.08 \mathrm{MPa}$, respectively (Figure $3, J$ and $L$ ). Positive stress values correspond to tensile stress where TAV leaflets stretched to close, whereas negative stress values represent leaflet compression or bending where redundant tissue was compressed to close. Stress contours for each region are shown in Figure 3.

Region 3 (sutured edges) contained the maximum and minimum principal stresses for the entire leaflet assembly (Figure 3, I-L). Peak stress occurred at tips of leaflet commissures along the attachment with the stent (Figure 2). In contrast, regions of free leaflet margin at the top and leaflet belly at the bottom had much lower peak stresses. Upper free leaflet edges (region 1) had maximum (1.31 and $1.75 \mathrm{MPa}$ at 80 and $120 \mathrm{~mm} \mathrm{Hg}$, respectively) and minimum ( -0.29 and $-0.51 \mathrm{MPa}$ at 80 and $120 \mathrm{~mm} \mathrm{Hg}$, respectively) principal stresses in the region where commissure attached to the stent (Figure 3, $A-D$ ). Lower leaflet belly (region 2) had maximum (1.25 and $1.69 \mathrm{MPa}$ at 80 and $120 \mathrm{~mm} \mathrm{Hg}$, respectively) and minimum $(-0.45$ and $-0.91 \mathrm{MPa}$ at 80 and $120 \mathrm{~mm} \mathrm{Hg}$, respectively)
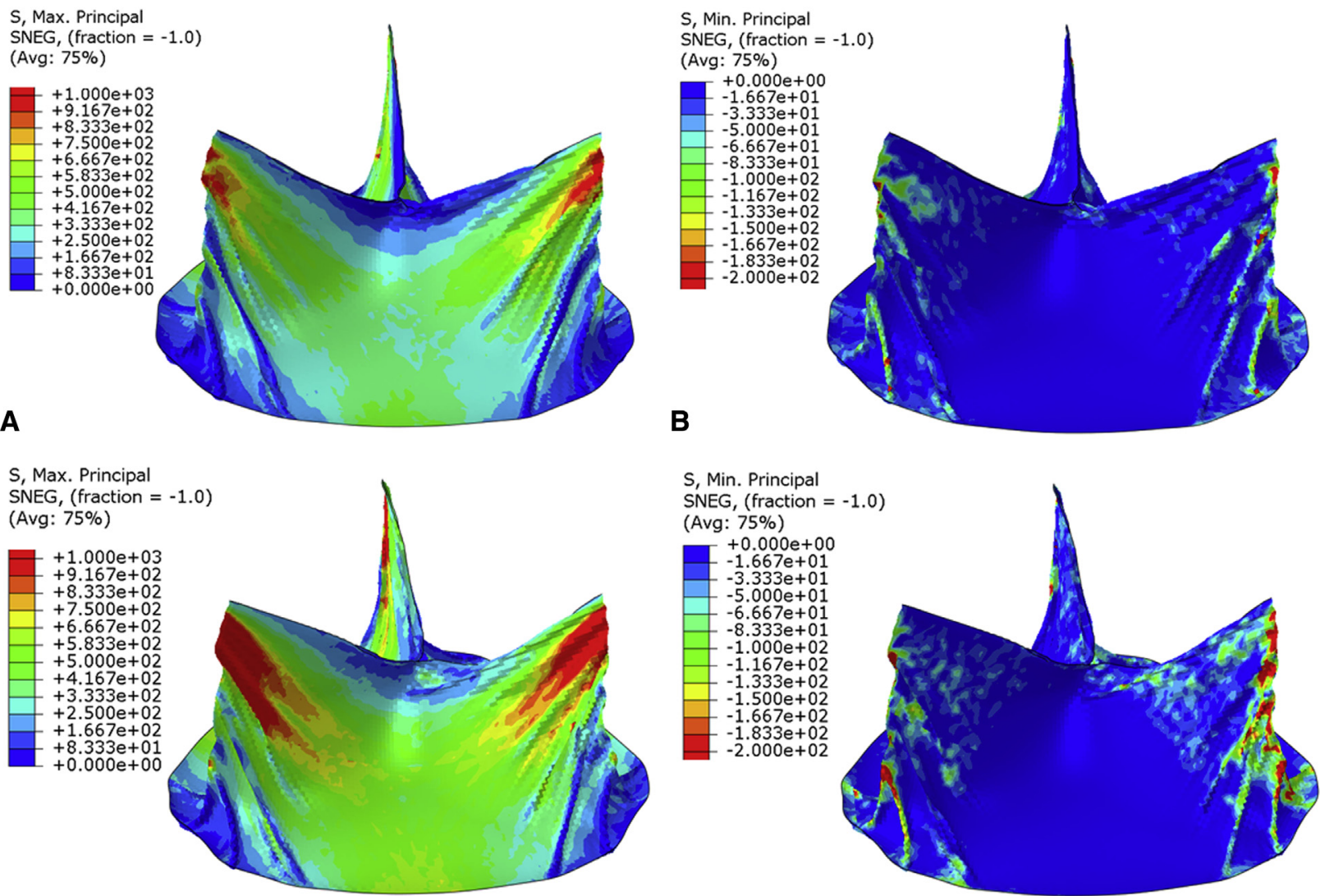

C

D

FIGURE 2. Principal stresses on entire leaflet assembly at $80 \mathrm{~mm} \mathrm{Hg}$ under quasistatic conditions. A, Maximum. B, Minimum. Principal stresses on entire leaflet at $120 \mathrm{~mm} \mathrm{Hg}$ under quasistatic conditions. C, Maximum. D, Minimum. 


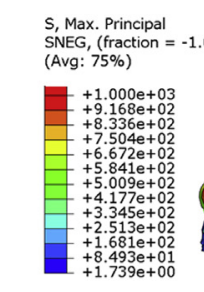

A

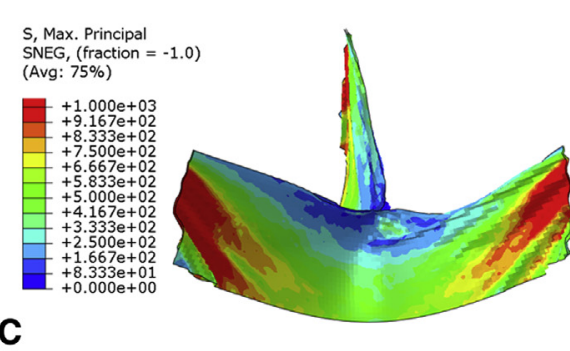

C

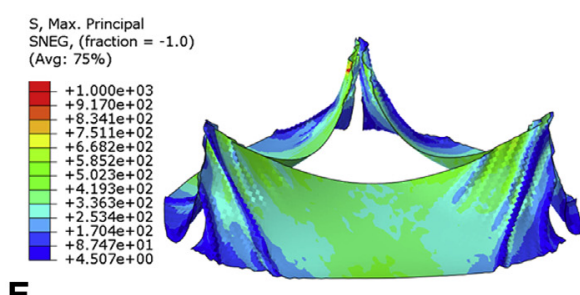

E

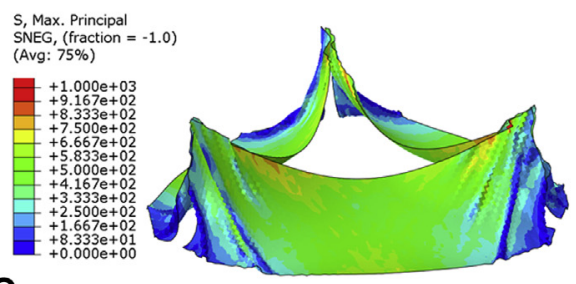

G

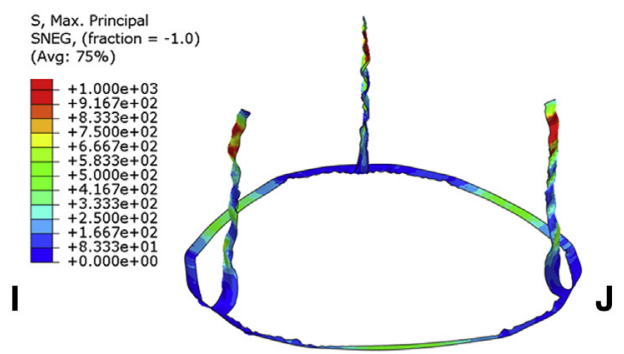

H

$\mathbf{F}$

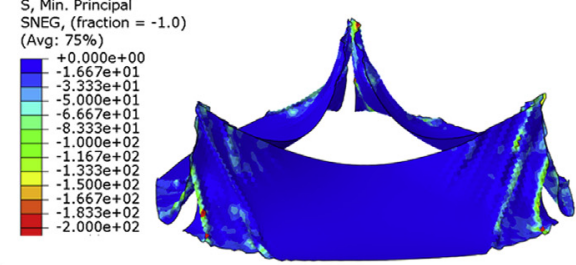

S, Min. Principal
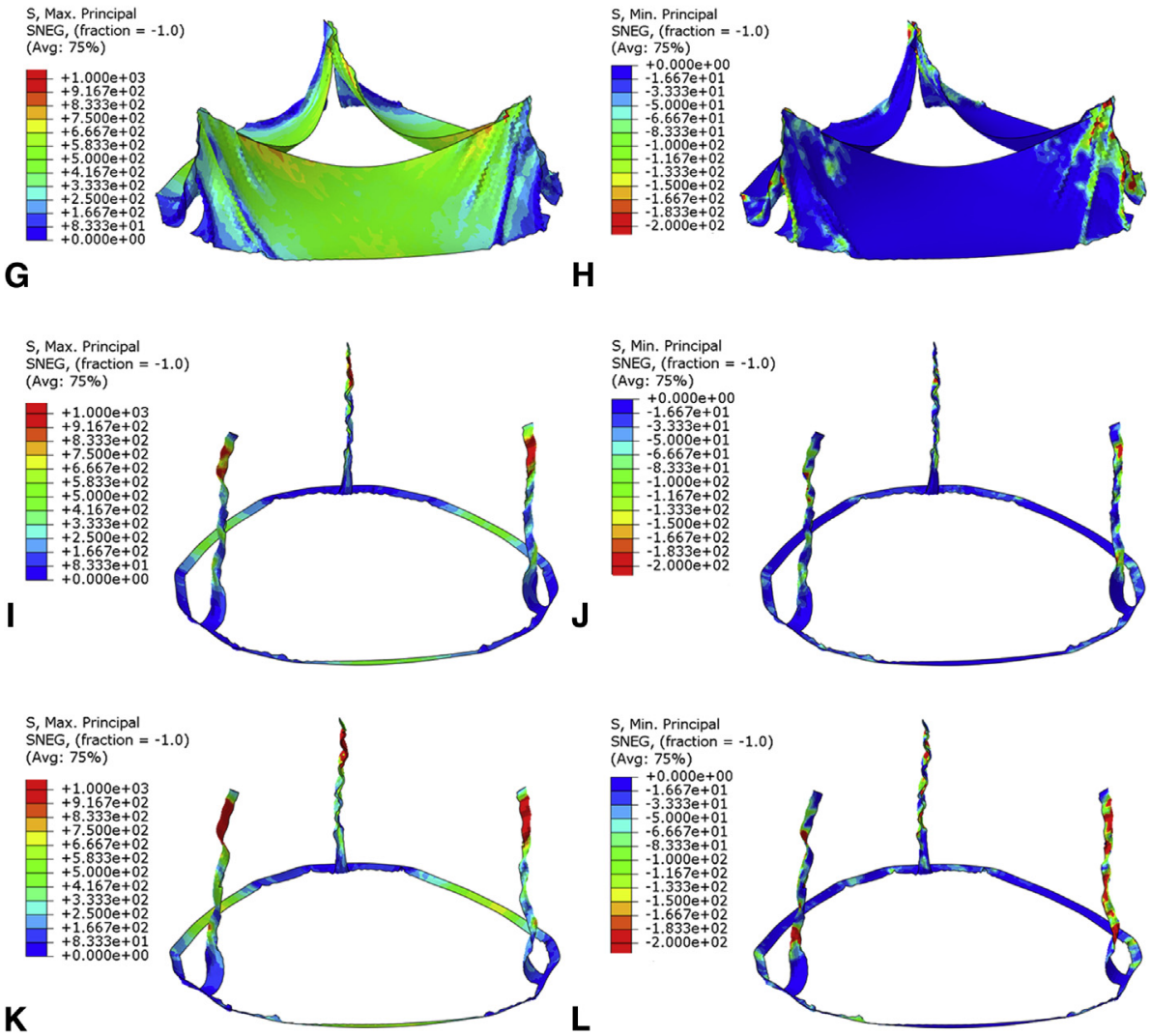

$\mathbf{L}$

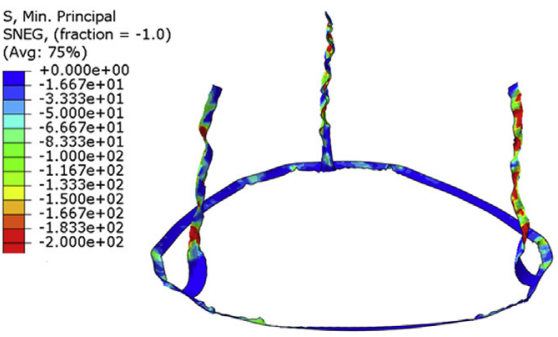

FIGURE 3. Under quasistatic conditions for region 1, principal stress at $80 \mathrm{~mm} \mathrm{Hg.} \mathrm{A,} \mathrm{Maximum} \mathrm{B,} \mathrm{Minimum.} \mathrm{Principal} \mathrm{stress} \mathrm{at} 120 \mathrm{~mm} \mathrm{Hg}$. C, Maximum. D, Minimum. For region 2, principal stresses at $80 \mathrm{~mm} \mathrm{Hg}$. E, Maximum. F, Minimum. Principal stresses at $120 \mathrm{~mm} \mathrm{Hg.} \mathrm{G,} \mathrm{Maximum.} \mathrm{H,}$ Minimum. For region 3, principal stresses at $80 \mathrm{~mm} \mathrm{Hg}$. I, Maximum. J, Minimum. Principal stresses at $120 \mathrm{~mm} \mathrm{Hg}$. K, Maximum. L, Minimum. 


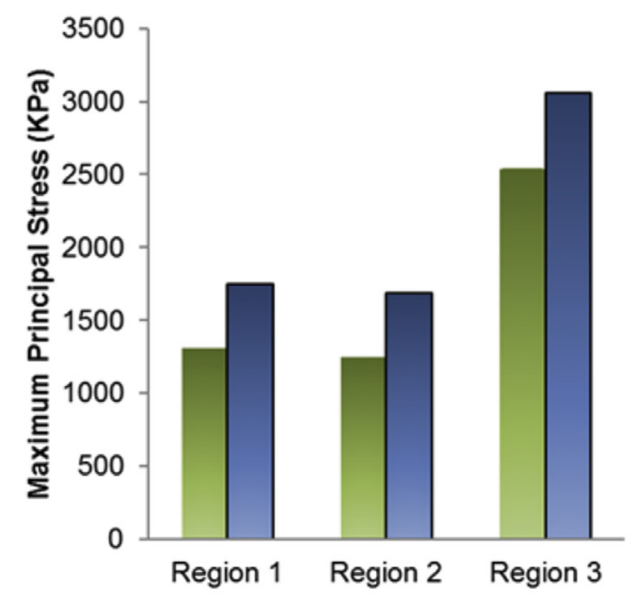

A

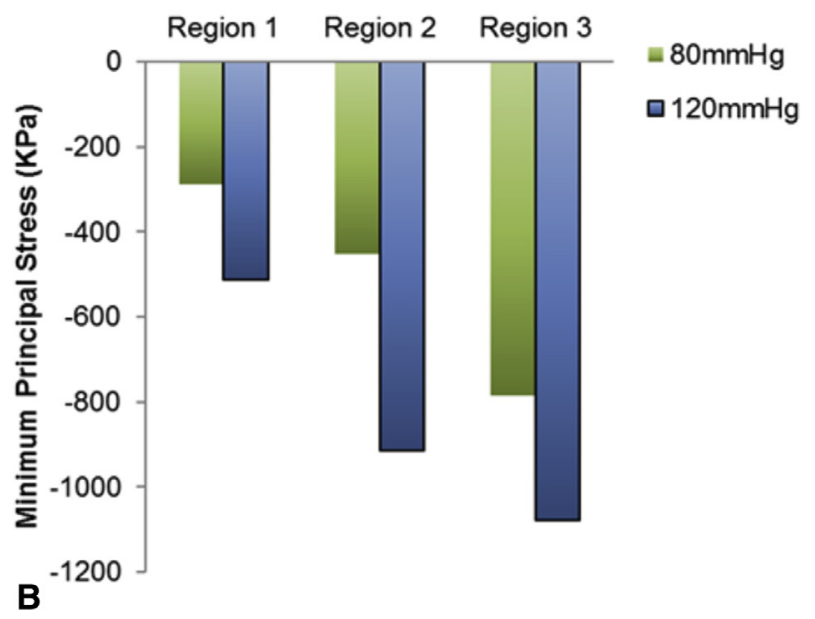

FIGURE 4. Comparison of principal stress contours for the 3 leaflet regions of interest at 80 and $120 \mathrm{~mm} \mathrm{Hg}$ at quasistatic loading conditions. A, Maximum and B, Minimum.

principal stresses, and stress was evenly distributed in the area of leaflet belly (Figure 3, E-H). Comparison of principal stresses for each leaflet region is plotted (Figure 4). The maximum principal stress of the TAV at diastolic pressure is presented online (Video 1).

For this TAV stent, maximum principal stresses at 80 and $120 \mathrm{~mm} \mathrm{Hg}$ were 188.91 and $251.98 \mathrm{MPa}$, respectively. Minimum principal stresses at 80 and $120 \mathrm{~mm} \mathrm{Hg}$ were -258.49 and $-362.99 \mathrm{MPa}$, respectively (Figure 5). Peak stresses occurred where longitudinal motion was constrained, at the proximal deployment in the annulus, and where the leaflets were attached to stent/commissural posts. Maximum stress was present on the outside surface, whereas minimum stress was present on the inner surface.

The distorted noncylindrical TAV had an eccentricity of 0.127 (minimum diameter/maximum diameter). It is the largest eccentricity reported by a post-TAVR clinical study of Sapien valves. ${ }^{15}$ For the distorted leaflets, upper free leaflet edges had maximum principal stress of $1.52 \mathrm{MPa}$

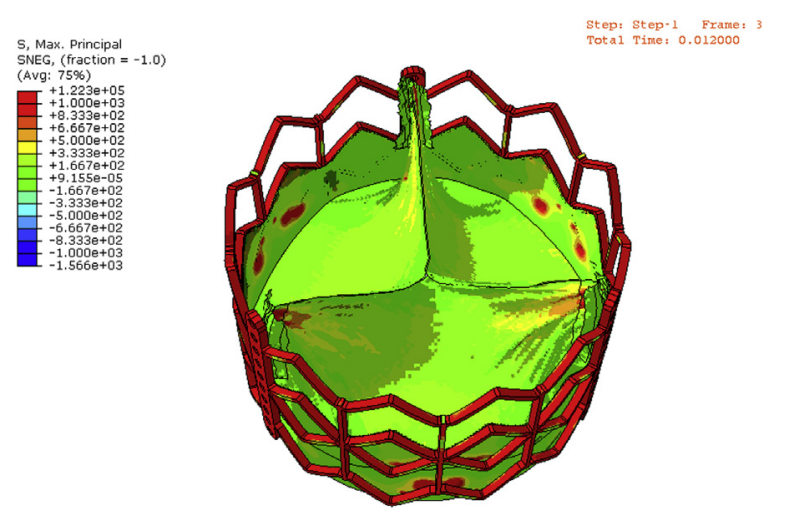

VIDEO 1. Maximum principal stress on a 26-mm Sapien Transcatheter Aortic Valve's (Edwards Lifesciences, Irvine, Calif) leaflets and stent under quasistatic diastolic pressure. Video available at: http://www.jtcvsonline. org/article/S0022-5223(16)31806-2/addons.

(Figure $6, A$ ) and minimum principal stress of $-0.36 \mathrm{MPa}$ at $80 \mathrm{~mm} \mathrm{Hg}$. The peak stress was located at the commissures where leaflets were attached to the stent, similar to that of cylindrical geometry. The lower leaflet belly had a maximum principal stress of $0.83 \mathrm{MPa}$ and minimum principal stress of $-0.36 \mathrm{MPa}$ at $80 \mathrm{~mm} \mathrm{Hg}$. The stent had maximum principal stress of $178.29 \mathrm{MPa}$ (Figure 6, B) and minimum principal stress of $-244.39 \mathrm{MPa}$ at $80 \mathrm{~mm} \mathrm{Hg}$.

\section{DISCUSSION}

From the initiation of the PARTNER trial in 2007 to commercialization of the Edwards Sapien XT in 2014, the majority of patients in the United States received a firstgeneration Sapien TAV. However, the long-term durability of this valve design or its subsequent iterations is unknown. The 5-year outcomes of the PARTNER trial revealed no structural valve dysfunction with maintenance of low gradients and increased valve area. ${ }^{16}$ Short-term durability thus appears adequate, but much longer-term follow-up is required. The Sapien valve was designed using bovine pericardium treated by the same anticalcification processes as the surgical Carpentier-Edwards aortic pericardial valves. ${ }^{17}$ Due to the size constraints of TAVR 22 Fr and 24 Fr delivery systems, TAV leaflets need to be thinner than surgical bioprostheses. Indeed, reduction further to $18 \mathrm{Fr}$ then $14 \mathrm{Fr}$ delivery systems for the Sapien XT and the third-generation Sapien 3 (Edwards Lifesciences, Inc), respectively, required altering stent material to cobalt-chromium and thinner leaflets to achieve a lower crimped TAV profile. Thinner leaflets translate into higher leaflet stresses unless compensated for by improvements in valve design. Leaflet stresses cannot be measured, but require FE modeling to determine. Accurate FE models require precise 3D geometry in a zero-stress state, material properties, and physiologic loading conditions. Previous FEA studies have attempted to determine 

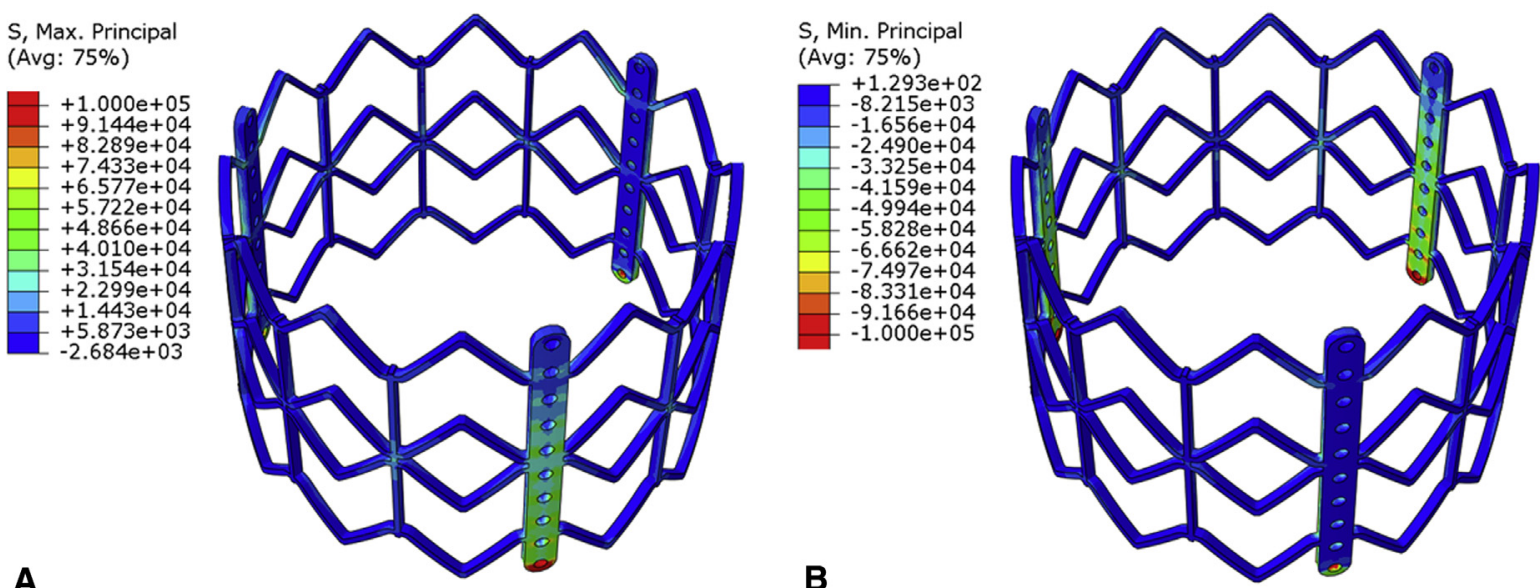

A

B
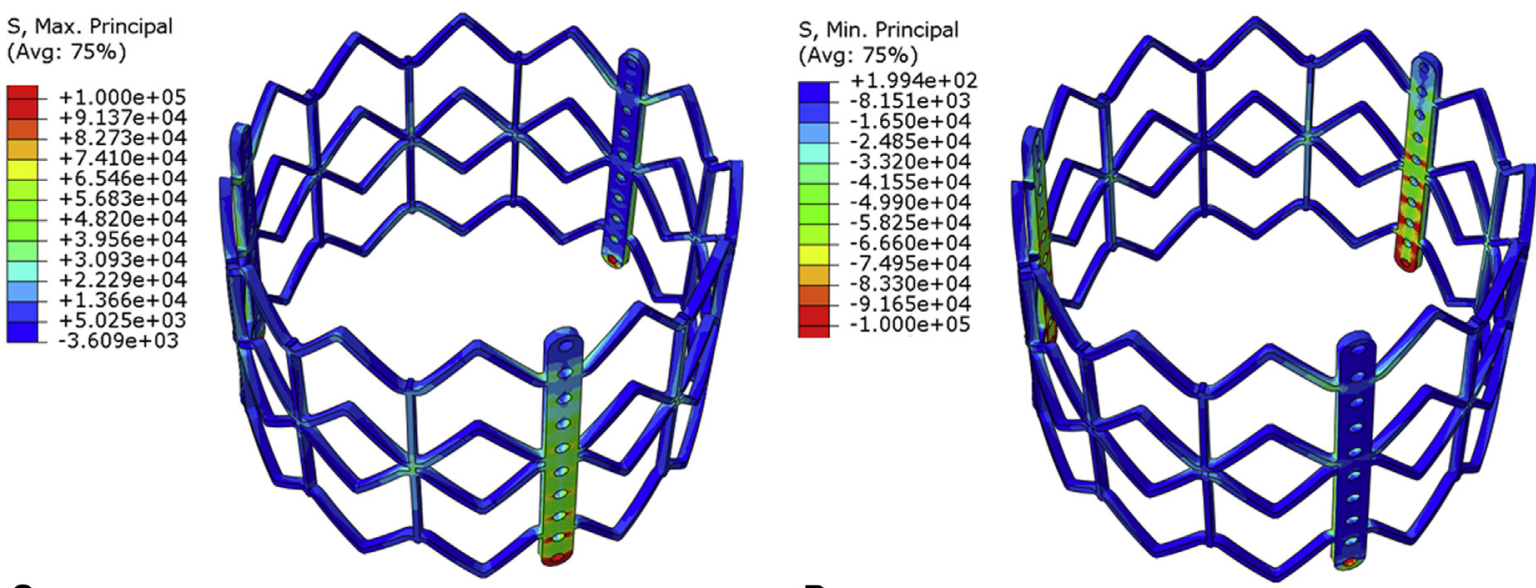

C

D

FIGURE 5. Under quasistatic loading, principal stresses of stent at $80 \mathrm{~mm} \mathrm{Hg}$. A, Maximum. B, Minimum. Under quasistatic loading, principal stresses at $120 \mathrm{~mm} \mathrm{Hg.} \mathrm{C,} \mathrm{Maximum.} \mathrm{D,} \mathrm{Minimum.}$

TAV leaflet stresses using a generic estimated leaflet geometry based on surgical valves and homemade TAVs. ${ }^{18,19}$ However, exact TAV - particularly leaflet—geometry was not used. On the other hand, patient-specific FEA simulations have used exact TAV stent geometry to investigate the interaction of TAV stent with surrounding aortic root geometry, but did not focus on precise TAV leaflet geometry and thereby stresses. ${ }^{20-22}$ Our study focused on FEA of TAV stresses using high-resolution micro-CT imaging of a Sapien valve to obtain accurate 3D geometry at nominal dimensions as a benchmark for comparison with future generations of TAVs or surgical valves.

In this study, we demonstrated that maximum and minimum principal stresses in 26-mm Sapien valves occurred proximally in the annulus, where the stent was deployed and confined. Overall, maximum and minimum principal stresses occurred where TAV leaflets were attached to the stent at the commissures. For the flexible regions of TAV leaflets, peak stresses were in the upper, $V$-shaped area approaching the commissure at systolic pressure. These regions of peak stress or locally higher stresses would be areas most prone to initiating degeneration. Relative durability of TAVR compared with surgical bioprostheses clinically is unknown. In studies of surgical bioprostheses, degeneration by calcification or leaflet tearing correlated with areas of high tensile and compressive stresses ${ }^{23}$ as well as cyclic flexural fatigue and bending. ${ }^{12}$ Sacks and colleagues ${ }^{11}$ performed FEA of 2 Edwards Lifesciences Inc bovine pericardial valves under $120 \mathrm{~mm} \mathrm{Hg}$ quasistatic loading conditions, with leaflet material properties determined from those valves and exact valve geometry. ${ }^{11}$ Depending on which leaflet material properties were used, maximum in-plane stress ranged from 544.7 kilopascals $(\mathrm{kPa})$ to $663.2 \mathrm{kPa}$. Leaflet stresses were greatest near the commissures and least near the free edge. Based on subsequent studies, their study used a $25-\mathrm{mm}$ surgical bioprosthesis, which is the most similar in size to our 26-mm Sapien valve. Leaflet attachment to the stent can influence leaflet stress and their study attached the leaflets to the wire frame of the surgical bioprosthesis. In our study, maximum principal stress for a $26-\mathrm{mm}$ Sapien valve was significantly higher than that reported for a surgical 


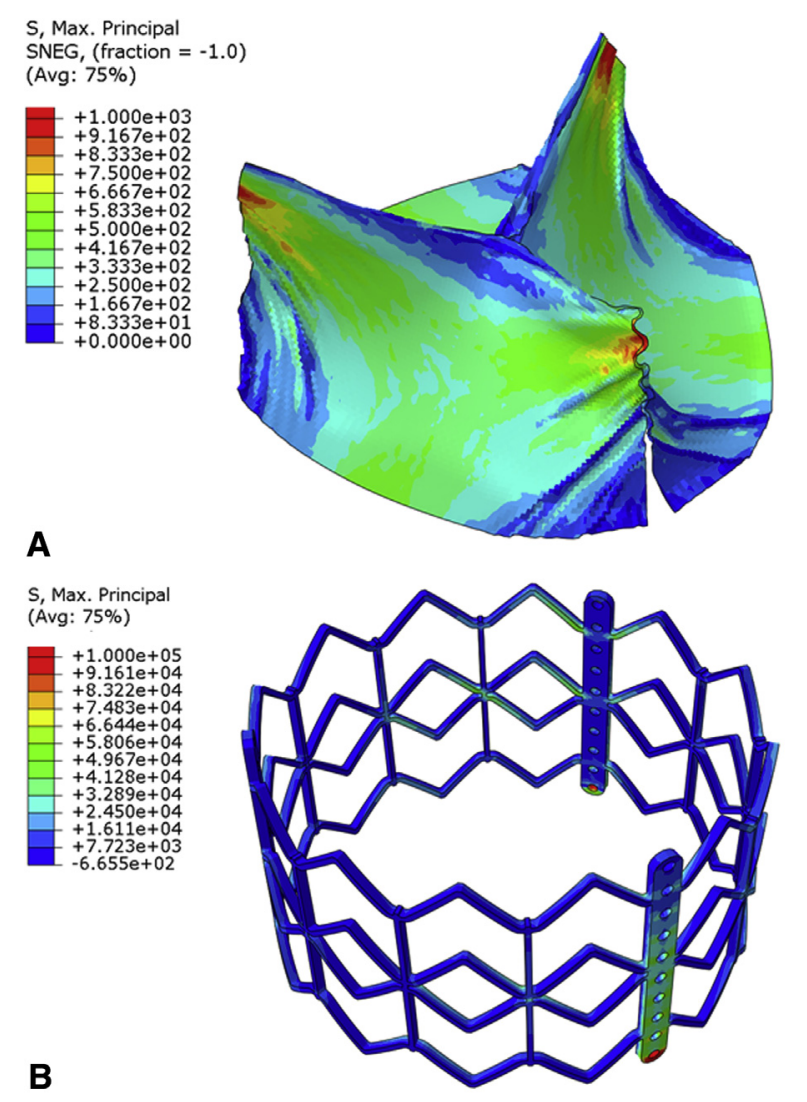

FIGURE 6. For the noncylindrical geometry, maximum principal stress at $80 \mathrm{~mm} \mathrm{Hg}$. A, Leaflet top and bottom. B, Stent.

bioprosthesis, which may reflect differences in leaflet design or leaflet interaction with their respective frames. Chandran and colleagues ${ }^{24}$ performed a dynamic FEA simulation with physiologic arterial pressures of a $23-\mathrm{mm}$ bovine pericardial Edwards bioprosthesis. ${ }^{24}$ They demonstrated peak von Mises stress of 2.09 MPa located at the cuspal commissures in the fully closed position. Peak stresses increased significantly with dynamic leaflet motion. Our simulation yielded higher peak von Mises stresses of 3.72 $\mathrm{MPa}$ in the quasistatic condition. Direct comparisons with results from the study by Chandran and colleagues ${ }^{24}$ are not possible because larger valve sizes may have higher stresses and Chandran and colleagues studied a 23-mm bioprosthesis. However, these studies suggest that dynamic simulations of a 26-mm Sapien valve may yield higher leaflet stresses.

\section{Comparison with TAV Simulations}

$\mathrm{Li}$ and $\mathrm{Sun}^{18}$ performed quasistatic simulations to $120 \mathrm{~mm} \mathrm{Hg}$ of TAVs using estimated leaflet geometry (ie, 22-mm leaflet diameter) and varying thickness of porcine and bovine pericardium. Maximum principal stress was $915.62 \mathrm{kPa}$ for bovine and $1565.80 \mathrm{kPa}$ for porcine pericardial leaflets at the fully loaded position. Thinner leaflets resulted in higher stresses and peak stresses occurred along the leaflet-stent attachment along the commissures. Another study, by Abasi and colleagues, ${ }^{25}$ reported maximum principal stress of $2.52 \mathrm{MPa}$ of a $23-\mathrm{mm}$ homemade TAV. None of the above studies included a fully assembled TAV with leaflets, stent, polyethylene terephthalate, and sutures as in our study. Our study shows greater leaflet stresses than previously reported peak stresses, and those differences may reflect our larger TAV diameter, incorporation of stent and polyethylene terephthalate to reflect interactive constraints on leaflets, and exact leaflet geometry and thickness.

Several studies have examined the Sapien TAVR in patientspecific simulations, ${ }^{20,21}$ using computed tomography images for geometry. They investigated biomechanical interactions of TAV stents with the surrounding calcified aortic valve and root to determine risk of coronary obstruction, paravalvular leak, and aortic root rupture. They typically ignored TAV leaflets in simulation and none reported leaflet stresses. Morganti and colleagues ${ }^{21}$ performed 26-mm Sapien XT TAVR simulations in 2 patients and examined stresses in the aortic root to estimate risk of rupture. They did demonstrate evidence of leaflet asymmetry based on patient-specific anatomy, but did not report the influence of asymmetry on TAV leaflet stresses. Sun and colleagues ${ }^{14}$ investigated the influence of TAVR deployment asymmetry on leaflet stresses in a generic $23-\mathrm{mm}$ TAV. They found peak leaflet stresses increased by $58.6 \%$ and $143.2 \%$ depending on the orientation of ellipticity. Maximum principal stresses increased from a baseline of $\sim$ $900 \mathrm{kPa}$ for complete leaflet symmetry to 1.1 to $2.2 \mathrm{MPa}$ depending on degree of eccentricity and orientation of ellipticity. Our baseline TAV stresses with leaflet symmetry was higher than their results due to our valve size and use of precise leaflet geometry and thickness. For noncylindrical distorted geometry, peak first principal stress increased $16 \%$ in our model deployed asymmetrically, which fell within the incremental range of the previous study. ${ }^{14}$ Clinical studies of Sapien valves did not reveal the extremes of ellipticity demonstrated in the study by Sun and colleagues. ${ }^{14}$

\section{Study Limitations}

Our study did not take into account the crimping and ballooning processes that occur during TAVR. Studies have demonstrated that the crimping process physically damages TAV leaflets and may weaken leaflets and increase leaflet stress. ${ }^{26}$ We did not destroy our TAV to test its leaflets for exact material properties given the rarity of obtaining TAVs and need for future TAV experimental in vitro tests, which are beyond the scope of this study. We used excised leaflets from surgical bioprostheses to determine the material properties of TAV leaflets. Although treatment processes for both Edwards valves are expected to be the same, thinner pericardial leaflets used in TAVRs may have different material properties ${ }^{18}$ than were represented here. Because stent and leaflet stresses cannot be directly 
measured, our analyses of stress cannot be experimentally validated. Determinations of strain experimentally are beyond the scope of this work and will be considered for future studies. Complex fluid-structure interaction simulations were not incorporated and are beyond the scope of this study. Geometry used in this work was based on a single $26-\mathrm{mm}$ Sapien valve. The manufacturing process can introduce geometrical variations. Their influence on the stress results was not investigated in this study. We used averaged material properties and pressure loading conditions for stress analysis and the results should be considered as the averaged or representative stress results. Lastly, the current study does not include simulation of a surgical aortic valve replacement of the same size but rather compared our results with a previous study, which may not correlate exactly for quantitative comparisons. ${ }^{11}$

\section{CONCLUSIONS}

We determined TAV stent and leaflet stresses on a 26-mm Sapien valve using exact geometry. We demonstrated that maximum stresses occurred at the stent proximally in the annulus where leaflets were attached, and at leaflet commissures where they attached to the stent. These leaflet regions will likely be areas where degeneration initiates. Future comparisons with surgical bioprostheses of comparable size will be necessary to compare relative durability based on valve design.

\section{Conflict of Interest Statement}

Dr Ye reports consulting fees from Edwards Lifesciences and JC Medical Inc. Dr Dvir reports consulting fees from from Edwards Lifesciences, Medtronic, St. Jude, and Gore. All other authors have nothing to disclose with regard to commercial support.

\section{References}

1. Cribier A, Eltchaninoff H, Bash A, Borenstein N, Tron C, Bauer F, et al. Percutaneous transcatheter implantation of an aortic valve prosthesis for calcific aortic stenosis first human case description. Circulation. 2002;106:3006-8.

2. Leon MB, Smith CR, Mack M, Miller DC, Moses JW, Svensson LG, et al. Transcatheter aortic-valve implantation for aortic stenosis in patients who cannot undergo surgery. N Engl J Med. 2010;363:1597-607.

3. Smith CR, Leon MB, Mack MJ, Miller DC, Moses JW, Svensson LG, et al. Transcatheter versus surgical aortic-valve replacement in high-risk patients. $N$ Engl J Med. 2011;364:2187-98.

4. Ye J, Cheung A, Lichtenstein SV, Altwegg LA, Wong DR, Carere RG, et al. Transapical transcatheter aortic valve implantation: 1-year outcome in 26 patients. J Thorac Cardiovasc Surg. 2009;137:167-73.

5. Ye J, Cheung A, Lichtenstein SV, Nietlispach F, Albugami S, Masson JB, et al. Transapical transcatheter aortic valve implantation: follow-up to 3 years. $J$ Thorac Cardiovasc Surg. 2010;139:1107-13.e1.

6. Crouch G, Bennetts J, Sinhal A, Tully PJ, Leong DP, Bradbrook C, et al. Early effects of transcatheter aortic valve implantation and aortic valve replacement on myocardial function and aortic valve hemodynamics: insights from cardiovascular magnetic resonance imaging. J Thorac Cardiovasc Surg. 2015; 149:462-70.
7. Leon MB, Smith CR, Mack MJ, Makkar RR, Svensson LG, Kodali SK, et al. Transcatheter or surgical aortic-valve replacement in intermediate-risk patients N Engl J Med. 2016;374:1609-20.

8. Bourguignon T, Bouquiaux-Stablo A-L, Candolfi P, Mirza A, Loardi C, May MA, et al. Very long-term outcomes of the Carpentier-Edwards Perimount valve in aortic position. Ann Thorac Surg. 2015;99:831-7.

9. Stamou SC, Williams ML, Gunn TM, Hagberg RC, Lobdell KW, Kouchoukos NT. Aortic root surgery in the United States: a report from the Society of Thoracic Surgeons database. J Thorac Cardiovasc Surg. 2015;149: 116-22.

10. Johnston DR, Soltesz EG, Vakil N, Rajeswaran J, Roselli EE, Sabik JF III, et al. Long-term durability of bioprosthetic aortic valves: implications from 12,569 implants. Ann Thorac Surg. 2015;99:1239-47.

11. Sun W, Abad A, Sacks MS. Simulated bioprosthetic heart valve deformation under quasi-static loading. J Biomech Eng. 2005;127:905-14.

12. Martin C, Sun W. Simulation of long-term fatigue damage in bioprosthetic hear valves: effects of leaflet and stent elastic properties. Biomechan Modeling Mechanobiol. 2014;13:759-70.

13. Jensen HA, Condado JF, Devireddy C, Binongo J, Leshnower BG, Babaliaros V, et al. Minimalist transcatheter aortic valve replacement: the new standard for surgeons and cardiologists using transfemoral access? J Thorac Cardiovasc Surg. 2015;150:833-40.

14. Sun W, Li K, Sirois E. Simulated elliptical bioprosthetic valve deformation: implications for asymmetric transcatheter valve deployment. J Biomechan. 2010 43:3085-90.

15. Willson AB, Webb JG, Gurvitch R, Wood DA, Toggweiler S, Binder R, et al Structural integrity of balloon-expandable stents after transcatheter aortic valve replacement assessment by multidetector computed tomography. JACC Cardiovasc Interv. 2012;5:525-32

16. Kapadia SR, Leon MB, Makkar RR, Tuzcu EM, Svensson LG Kodali S, et al. 5-year outcomes of transcatheter aortic valve replacement compared with standard treatment for patients with inoperable aortic stenosis (PARTNER 1): a randomised controlled trial. Lancet. 2015;385:2485-91.

17. Tseng E, Wisneski A, Azadani A, Ge L. Engineering perspective on transcatheter aortic valve mplantation. Interv Cardiol. 2013;5:53-70.

18. Li K, Sun W. Simulated thin pericardial bioprosthetic valve leaflet deformation under static pressure-only loading conditions: implications for percutaneous valves. Ann Biomed Engineer. 2010;38:2690-701.

19. Bailey J, Curzen N, Bressloff NW. Assessing the impact of including leaflets in the simulation of TAVI deployment into a patient-specific aortic root. Comput Methods Biomech Biomed Engin. 2016;19:733-44.

20. Wang Q, Sirois E, Sun W. Patient-specific modeling of biomechanical interaction in transcatheter aortic valve deployment. J Biomech. 2012;45 1965-71.

21. Morganti S, Conti M, Aiello M, Valentini A, Mazzola A, Reali A, et al. Simulation of transcatheter aortic valve implantation through patientspecific finite element analysis: two clinical cases. J Biomechan. 2014; 47:2547-55

22. Russ C, Hopf R, Hirsch S, Sündermann S, Falk V, Székely G, Gessat M. Simulation of transcatheter aortic valve implantation under consideration of leaflet calcification. 35th Annual International Conference of the IEEE EMBC. 2013;711-4.

23. Vesely I. The evolution of bioprosthetic heart valve design and its impact on durability. Cardiovasc Pathol. 2003;12:277-86.

24. Kim H, Lu J, Sacks MS, Chandran KB. Dynamic simulation of bioprosthetic heart valves using a stress resultant shell model. Ann Biomed Eng. 2008;36: 262-75.

25. Abbasi M, Azadani AN. Leaflet stress and strain distributions following incomplete transcatheter aortic valve expansion. J Biomechan. 2015;48: 3663-71.

26. Alavi SH, Groves EM, Kheradvar A. The effects of transcatheter valve crimping on pericardial leaflets. Ann Thorac Surg. 2014;97:1260-6.

Key Words: transcatheter aortic valve, durability, stress, finite element 